\title{
Implanting a Discipline: The Academic Trajectory of Nuclear Engineering in the USA and UK
}

\author{
Sean F. Johnston
}

(C) Springer Science+Business Media B.V. 2009

\begin{abstract}
The nuclear engineer emerged as a new form of recognised technical professional between 1940 and the early 1960s as nuclear fission, the chain reaction and their applications were explored. The institutionalization of nuclear engineering-channelled into new national laboratories and corporate design offices during the decade after the war, and hurried into academic venues thereafter-proved unusually dependent on government definition and support. This paper contrasts the distinct histories of the new discipline in the USA and UK (and, more briefly, Canada). In the segregated and influential environments of institutional laboratories and factories, historical actors such as physicist Walter Zinn in the USA and industrial chemist Christopher Hinton in the UK proved influential in shaping the roles and perceptions of nuclear specialists. More broadly, I argue that the Statemanaged implantation of the new subject within further and higher education curricula was shaped strongly by distinct political and economic contexts in which secrecy, postwar prestige and differing industrial cultures were decisive factors.
\end{abstract}

Keywords Discipline - Nuclear engineer - University · Expertise · Training · National laboratory

\section{Introduction}

During the twentieth century, and particularly from the 1930s, nuclear physics was one of the most rapidly growing fields of scientific knowledge. Dramatically accelerated by the Second World War, this expertise was marshalled to develop not just the first nuclear weapons but also civilian applications. The post-war capabilities of 'atomic energy'-copious production of radiation to transmute

S. F. Johnston $(\bowtie)$

University of Glasgow, Dumfries Campus, Glasgow DG1 4ZL, UK

e-mail: s.johnston@crichton.gla.ac.uk 
elements, to create radioisotopes for medical applications and to generate powergrew in tandem with the new field of nuclear engineering. Owing to the strategic importance of the subject for military supremacy, national prestige, energy policy and international trade, the discipline, occupation and profession of nuclear engineering were driven by government definition and support. ${ }^{1}$

Accounts of the field have focused on its wartime origins, particularly of key historical actors (e.g. Compton 1956, Hartcup and Allibone 1984, Brown 1997; Bernstein 2004), policy-making (Gowing 1964; Hewlett and Duncan 1969) and the development of commercial nuclear power (Pocock 1977; Bothwell 1988). Comparisons of nuclear programs (de Leon 1979) and of the identity of engineering professions (Downey and Lucena 2004) have contrasted differing national contexts. However, nuclear engineering as a body of expertise has attracted relatively little attention, and studies of its academic origins are sparse.

I argue that this lack of attention to its specialists is a consequence of the unusual context in which nuclear engineering developed. In an environment of secrecy and military urgency during the war and for a decade thereafter, practitioners were restricted from open academic discourse; indeed, apart from a handful of highprofile scientists publicly representing the new domain, the early historical actors and developing expertise were largely invisible. As a result, nuclear engineers were peculiarly voiceless, and the development of self-perception and shared identity was constrained. From the mid 1950s, though, national haste to demonstrate peaceful civilian applications pushed nuclear engineering into university curricula. A consequence for the historian is a relative dearth of documents relating to nascent community identity and aspirations, but more readily traced emergence of the academic discipline.

This paper contrasts the distinct histories of nuclear engineering's academic embedding in the countries that had first collaborated in the field as wartime allies: the USA, UK and (more briefly) Canada. It documents an atypical disciplinary trajectory in which governments played the key role in defining intellectual content, occupational categories and professional aspirations for the emerging field. Implantation of the discipline within further and higher education curricula was shaped strongly by political and economic contexts, and was configured differently in each country owing to distinct national goals and administrative cultures.

\section{Core Knowledge}

The root of nuclear engineering's disparate trajectories lay in dissimilar conceptions of how the intellectual subject and its skills set should be constituted. The novelty of this engineering domain was disputed. Its proponents focused on new intellectual expertise supporting a novel occupational context: the design and operation of

\footnotetext{
${ }^{1}$ By 'discipline' I mean the intellectual foundations, specialized skills, educational institutionalization and academic allegiances supporting a self-recognised coherent body of knowledge. I distinguish this from the aspects of 'occupation' - the pursuit of productive activity — and 'profession' — the community interactions and recognised status attaching to disciplinary and occupational expertise. This distinction follows the approach of Abbott (1988) and of Divall and Johnston (2000).
} 
nuclear reactors. ${ }^{2}$ But how was the nuclear reactor perceived by, and involved in the shaping of, its creators and users?

On the face of it, the first reactors were mundane devices. Their original name, piles, mirrored their construction, originally a compact assembly or lattice-work mountain of materials. Their visible characteristics were also unexciting: such piles generated heat, which was removed either to keep them cool or to generate useful electrical power. For power generation, well-established engineering principles were applied-principles developed over the previous two centuries to collect and transfer the heat via an exchange medium such as water, steam or gas, and to convert it to mechanical motion and electrical power with turbines. Other design principles were just as traditionally established: how to package the materials in mechanical structures that were mechanically, structurally, chemically and thermally stable; and how to ensure reliable operation of these factory-sized environments of interlinked mechanical, electrical and thermal systems.

But the first reactors had unfamiliar purposes and invisible characteristics, too. Their goal, specified by the Manhattan Project, was to generate a sustained chainreaction of radioactive materials, and to use this controlled fission to transmute them into new elements, one of which (plutonium) would be used in bombs. ${ }^{3}$ This deeper function, revealed publicly after the war, was the source of their new name: chainreactors or, soon after, reactors. ${ }^{4}$

Underlying the potential of the chain reaction lay rapidly expanding knowledge of nuclear physics, chemistry and metallurgy and a comparable wave of novel engineering expertise. A more sophisticated variety of reactor, the so-called breeder, further advanced prospects for a specialist discipline. Conceived during the war as a means of avoiding the predicted limited world supply of uranium, the breeder reactor produces more radioactive fuel than it consumes, but at the expense of greater technical complexity. Most designs relied on energetic 'fast' neutrons to transmute natural uranium or thorium into plutonium, for which efficient chemical extraction and reprocessing techniques were needed. Typical designs required high radiation levels and temperatures in the core-both conditions little understood initially - and sophisticated liquid metal cooling systems for removal of heat. Its novel regime of operation demanded theoretical understandings and practical solutions well beyond conventional engineering knowledge, and offered a perpetual resource that would benefit from continual development, thus boosting the prospects of a specialist discipline of nuclear engineering.

\footnotetext{
${ }^{2}$ Indeed, institutions highlighted this new terrain. The UK Atomic Energy Authority vaunted its role to 'design, build and operate new types of reactor' (Jay 1956, p. v). Atomic Energy of Canada Ltd identified its business as 'creation of atomic energy' [Atomic Research Workers Union, No. 24291, Applicant-and Atomic Energy of Canada Limited, Respondent. LAC RG145 Vol 114 File 766:336:52].

3 The Nagasaki bomb was based on plutonium generated in nuclear reactors designed at the 'Metallurgical Laboratory' ('Met Lab') of the University of Chicago. By contrast, the Hiroshima uranium bomb relied on the separation of the isotope U-235 from the almost indistinguishable U-238 in uranium-rich ores, for which processes based on gaseous diffusion, electromagnetic separation and centrifuges were developed at Oak Ridge, Tennessee.

4 An alternate etymology credits wartime chemical engineers, designers of chemical 'reactors', with making an analogy between chemical and nuclear production. The competing origins are significant, as they attribute authority over the new domain to different technical specialists.
} 
As varieties of reactor systems proliferated, engineering knowledge developed alongside new scientific insights. For instance, the first plutonium production reactor, at Hanford, Washington, proved to be temporarily 'poisoned' by the production of an unexpected fission product which disastrously diminished the chain reaction rate (Carlisle and Zenzen 1996). Other operational discoveries revealed the alteration of structural properties of reactor materials by irradiation. And nuclear power reactors, despite functioning as mere heat generators, were qualitatively different from conventional power plants: the materials themselves were or could become radioactive, posing biological dangers that required elaborate safety systems. These invisible factors introduced unanticipated variables into the arts of metallurgy, thermal design, chemical engineering and mechanical engineering.

The nature of this hybrid discipline was, then, defined by the nuclear reactor and its multiple design parameters and products. Metallurgists and materials engineers were faced with unknown processes of distortion, embrittlement and transformation of fuel rods and cooling pipes, necessitating experimental testing in a reactor environment. Civil and mechanical engineers saw the reactor as a perversely precise large-scale construction. Thermal engineers tackled the challenge of extracting heat from the energy-dense core, and ensuring that these heat-transfer systems operated reliably in lethally radioactive environments barred to direct human manipulation. ${ }^{5}$ Chemical engineers developed processes to separate nearly identical elements, crucial in accumulating material for bombs or for reuse in reactors.

Nuclear engineering thus developed in a technical context that was both seductively familiar and thoroughly mysterious. Some professions-pipefitters and civil engineers, for example-felt confident to perform their traditional roles with only slightly extended knowledge and safety precautions. Others, such as metallurgists and chemical engineers, were required to accommodate new materials, technologies and constraints, transforming their disciplinary expertise in the process. And still other domains, such as reactor engineering and its experts, were wholly new.

\section{Secrecy, the State and Disciplinary Constraints}

This technical ground was explored on political terrain: wartime military and subsequent Cold War secrecy. Expertise in nuclear reactors was closely affiliated with knowledge useful for bomb production. Nevertheless, there was an early division of labour between designers of reactors and bombs at distinct locations. ${ }^{6}$ While both operated initially in secrecy, their intellectual environments and goals increasingly diverged. Bomb design was a particularly unfertile endpoint, providing

\footnotetext{
${ }^{5}$ Damage to early reactors by thermal run-away was not rare, although the later Three Mile Island (1979) and Chernobyl (1986) events gained greater public attention. Earlier incidents from which engineering experience was gleaned included those at NRX, the first large Canadian reactor (1952), Windscale (1957) in Britain, the Santa Susana Field Laboratory near Los Angeles (1959) and the SL-1 reactor in Idaho (1961).

${ }^{6}$ This separation was dictated early. Los Alamos and Aldermaston focused on bomb design in the USA and UK, respectively; Canada had no such site. Argonne and Oak Ridge (USA), Harwell (UK) and Chalk River (Canada) focused on reactor development.
} 
increasingly sophisticated weapons designs but a dearth of other applications under its self-limiting shroud of concealment. Nuclear reactors, on the other hand, could generate a spectrum of new isotopes. They encouraged the development of new chemical and physical processes, and promised open civilian benefits, from new forms of medical treatment to power generation. The broader promise of 'atomic energy', then, offered a convergence of interests to unite a variety of engineers, physicists, chemists and biologists in an inchoate field.

Its wartime origins and Cold War expansion nevertheless shaped the nascent discipline. Guarding the 'secret' of the atomic bomb (Herken 1980) preoccupied administrators of the Manhattan Project and its civilian successors in the USA, UK and Canada.

Periodic restrictions on nuclear information-sharing between the Allies during the war had been motivated by concerns about unequal exchange, potential commercial exploitation and loss of information to the Soviet Union. The secure wartime sites were geographically isolated. The US McMahon Act of 1946, seeking to contain this strategically important expertise, curtailed international collaboration and segregated research and development not only between but within the three countries. 'Atomic spy' scandals involving Allan Nunn May (1946), Klaus Fuchs (1950), Bruno Pontecorvo (1950) and Julius and Ethel Rosenberg (1951), linked to the atomic energy programs of all three countries, further heightened institutional suspicions of Soviet espionage. Senator Joseph McCarthy's hearings of 1950-1954 on communist infiltration of government encouraged the US Congress to require FBI security investigations of all National Laboratory employees and visitors.

British and Canadian security policies tightened in an attempt to safeguard their technical expertise and to reverse American isolationism. Indeed, Britain's post-war Division of Atomic Energy was more cautious than its American counterpart, restricting information about reactors, instrumentation and health physics and concealing its atomic bomb project from the public until the first detonation in 1952 . Security policies further inhibited unionisation and the formation of professional societies, the typical markers of technical identity. ${ }^{7}$

Mobility of specialist workers was constrained by fears of transporting secrets across national borders. The McMahon Act discouraged Americans from joining foreign establishments, and US security procedures excluded foreigners from most sites. For the same reason, specialist publications, training and academic exchange

\footnotetext{
7 Although differently configured in the USA, UK and Canada, labour representation for nuclear workers was shaped by secrecy. Until the early 1950s, collective representation was discouraged by the AEC on the grounds of national security, but the Commission did not actively resist unionisation efforts by the American Federation of Labour and later the Oil, Chemical and Atomic Workers' Union (1955). In Canada, without an overt military dimension to protect, new unions such as the Atomic Research Workers' Union (1952) emerged earlier to represent Chalk River workers, but promiscuously included those linked only by the occupational environment of atomic energy. In the UK, by contrast, workers were accommodated by existing unions; a short-lived Atomic Workers union disappeared in part owing to its lack of recognition by the UKAEA, which remained vigilant in discouraging left-wing sympathies [National Union of Atomic Workers 1958-63. NA FS 27/406]. Such State pressures are also discernable in the demise of the Atomic Scientists' Association in 1959 after government spokesmen criticised its report on the medical effects of fallout from the British H-bomb [The Atomic Scientists Association Ltd: policy and associated correspondence 1950-1951: 1954-1959. NA AB 27/6; Atomic Scientists Association's general correspondence 1946-1951. NA AB 16/52].
} 
were restricted; the field had no open scientific meetings, courses, journals and few books until the mid 1950s.

Secrecy, then, had a profound fallout for nuclear workers. It cloistered nuclear engineering expertise, encouraging nationally distinct specialists, and concentrated all aspects of discipline-building for the new field in the hands of government.

\section{The Nucleus of a Post-war Discipline}

\section{American Definition at National Laboratories}

At the centre of defining a new discipline lay the problem of training nuclear specialists. Teaching such topics - albeit classified material to screened audiencesbegan on a small scale in the USA immediately after the war. Administration of the wartime Manhattan Project facilities was transferred to the new Atomic Energy Commission (AEC) in 1946, with Argonne IL, Oak Ridge TN and Brookhaven NY becoming the first 'National Laboratories'. Formally dissociated from military development, they were conceived as a source of facilities, projects and expertise for academic researchers at regional American universities.

Walter Zinn, the first Director of Argonne National Lab (ANL), played an influential role in defining American nuclear engineering. As one of the most senior designers of wartime piles, he recognised that the expertise gained by the Chicago 'Met Lab' could be consolidated. Zinn focused the objectives of ANL on pile design, construction and fundamental research. ${ }^{8}$

Zinn's establishment accumulated workers with wartime experience. As a result, key designers and administrators in American nuclear engineering during the following decades had backgrounds rich in practically acquired knowledge. A typical example is Martin Shaw, who served at ANL as Director of the Division of Reactor Development and Technology from 1964 until the 1970s. Like Zinn, Shaw had notched up an impressive list of achievements in a career that grew with the subject. Having begun his career in engineering works, he served in the Navy during the war and obtained degrees in Mechanical Engineering after it. From the late 1940s, he rose in the Naval Reactors Program to direct the Navy's Advanced Design Division, and with responsibility for aspects of the first US nuclear power station at shipping port. Shaw was responsible for the conception of the first generation of submarine, nuclear aircraft carrier and nuclear cruiser power plants. And, after transfer to ANL, he assumed even heavier responsibilities: development of nuclear reactors for civilian and military applications, and nuclear safety. Career biographies such as Shaw's illustrate the close alliance between government-sponsored research, military development and civilian nuclear power in the USA, as well as the relatively weak role of universities in this even a quarter century after the first atomic bomb.

\footnotetext{
${ }^{8}$ University of Illinois archives, records of the Argonne Universities Association, Urbana-Champaign, Illinois, USA (henceforth UI) box 46.
} 
While Zinn's ANL strove to set the agenda for American nuclear engineering, Oak Ridge National Lab (ORNL) became the centre of early education. Its nucleus was Clinton Laboratories, wartime home of a reactor group spawned from the Met Lab. Seeking to establish a national role for themselves, its members fostered postwar government sponsorship and close links with academe, establishing a graduate studies partnership with the nearby University of Tennessee and links with Massachusetts Institute of Technology. Its educative role was consolidated by the separate Clinton Training School in 1946 (known informally as the 'Clinch College of Nuclear Knowledge'), focusing on nuclear engineering and physics rather than biological ramifications. Opened by Eugene Wigner (1902-1995) the former leader of the Met Lab reactor group, the School attracted some fifty participants from industry, academe and the military. Influential graduates included Martin Shaw and Captain Hyman Rickover (1900-1986), later the champion of a nuclear-based navy (Hewlett and Duncan 1974).

The Clinton Training School closed in 1947 when site management by the Monsanto Company ended, but fourteen south-eastern universities collaborated that year to form the Oak Ridge Institute of Nuclear Studies (ORINS), a governmentowned company-operated facility overseen by the new Atomic Energy Commission (Poor 1963). ORINS disseminated biologically oriented knowledge, more cleanly divorced from military applications than was reactor design. Faculty at the participating universities had access to the Institute's laboratory facilities. Knowhow on matters such as radiation protection and the medical applications of radioisotopes was provided to its member universities-with student numbers stabilizing at some 70 per year by 1950 - and further promoted by travelling lectures by the Institute's scientists.

A separate initiative, the Oak Ridge School of Reactor Technology (ORSORT), was founded in 1950 to provide classified expertise that universities could not provide (Oak Ridge National Laboratory 2002; Weinberg 1994). Organised by physicist Frederick Seitz (1911-2008), its faculty included a half-dozen physicists from Eugene Wigner's Met Lab group. American expertise and teaching, then, grew out of the cluster of physicists and engineers at ANL and ORNL who had emerged from Chicago's Met Lab.

Unlike ORINS, which occasionally granted access to Canadian and British workers, ORSORT was restricted to US citizens. ${ }^{9}$ Its first-year began with a complement of 46 solely government-sponsored students drawn from the AEC and military contractors; during 1951, most students were from industries drawn into reactor design and operation for the Navy; and, the majority of the following year's 81 students were those planning careers as nuclear workers at government-funded sites or with industrial contractors. Most attendees were college graduates holding Bachelor's degrees in chemistry, engineering, metallurgy, physics or engineering physics. As one administrator could argue privately, ORSORT had no academic rival:

While some universities have given occasional special courses... it appears that the group applying at Oak Ridge are attracted by feeling that the most

\footnotetext{
${ }^{9}$ Atomic Energy Commission (1953) Oak Ridge Operations Information Manual, Budget and Reports Division [accessed via http://www.osti.gov/opennet/detail.jsp?osti_id=16111668].
} 
authoritative information is received here and, based on our experience with ORSORT, would not return to the universities for short courses. ${ }^{10}$

ANL and ORNL thus played seminal roles, but other government sites helped shape the discipline. During this period production sites trained their workers for existing jobs and promotion to new ones. From the late 1940s the Hanford Technology Course taught topics including nuclear physics, instrumentation, chemistry and handling, and a more advanced Pile Technology Course focused on reactor operations. ${ }^{11}$ Similarly, from 1949 ANL sponsored an Atomic Energy Institute for some 2,400 teachers and administrators in Chicago area schools, and had provided special non-credit courses 'in the fields of chemistry, physics and reactor engineering with special emphasis on the unique aspects needed in atomic energy work'. ${ }^{12}$ Its administrators initially rejected the idea of 'formal fellowship programs akin to ORINS and ORSORT', preferring that their temporary staff members 'learn by direct experience in one of the Laboratory projects'. ${ }^{13}$

\section{British Reliance on Industrial Models}

Under the McMahon Act, national programs were largely independent. The wartime collaboration had nevertheless provided a model for the top-down construction of the field in the UK, and the US organisation and training was noted, if not directly experienced, by British nuclear workers. The United Kingdom Atomic Energy Authority (UKAEA, founded in 1954) trained its own workers mirroring American practice. The four-week Harwell Isotope School begun in 1951 (Herran 2006), and joined by a 12-week Reactor School in 1955, were similar to ORINS and ORSORT, respectively. Calder Hall, site of the first power reactor and operated by the Production Group, instituting an eight-week Operation School to train plant operators similar to its Hanford equivalent; by 1957 it had trained 42, in groups alternating between British and overseas (mainly Commonwealth) students.

Despite such similarities, the etymology of specialist labels reveals national distinctions. John Cockcroft, Director of Harwell, tentatively termed his workers, particularly those trained in the Harwell in-house courses, 'atomic energy technologists' (Cockcroft 1954). ${ }^{14}$ Significantly, this term was unpopular, and unsupported by labelled occupational posts. While American and Canadian

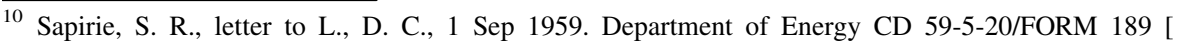
http://www.osti.gov/opennet/detail.jsp?osti_id=16289444]].

${ }^{11}$ Brown, C. L. personal notebook, Hanford Technology Course, 15 Oct 1948-8 Oct 1953. Department of Energy Declassified Document Retrieval System: Hanford Engineering Works archive (online database, henceforth DOE DDRS, accessed via http://www5.hanford.gov/ddrs) D198027813; DOE DDRS, Fullmer, G. C. personal notebook, Pile Technology Course, 26 Jan 1950-30 Sep 1960. DOE DDRS D198027813.

${ }^{12}$ Board of Governors' Minutes, Argonne National Laboratory, 2 May 1950. UI box 44.

13 Boyce, J. C. memo to Council of Participating Institutions, 26 Jan 1951. UI box 134.

14 The term technologist, rising in usage during the 1950s, reflects the new occupation promoted in the environment of government laboratories, in which scientists and engineers associated more closely than did their pre-war counterparts.
} 
institutions unproblematically adopted the term 'nuclear engineer' (even if the content of their special expertise initially was unclear), the British pointedly did not.

The different national trajectory can be ascribed to distinct working cultures and particularly the influence of one man, Christopher Hinton. Hinton had assumed responsibility for the UK's post-war industrial atomic facilities informed by his experiences as a former engineer at Imperial Chemical Industries (ICI) and senior wartime manager of chemical factories. His background encouraged him to categorise atomic energy and its specialists according to the working culture of ICI and the technical Civil Service. Compartmentalisation of nuclear facilities in the UK was different from that in the USA: while the Atomic Energy Research Establishment at Harwell corresponded to aspects of the Argonne and Oak Ridge National Laboratories, Hinton's Production Group had no direct parallel, and more consistently vaunted engineers over scientists.

With his unique responsibility for its industrial development in the UK unparalleled by American and Canadian counterparts-Hinton argued that the 'correct perspective' regarding nuclear energy was that it 'should not be regarded as a completely new technology, but rather as an extension and development of existing technologies' (Hinton 1956, p. 1). An editorialist in the journal Engineering reiterated this national attitude:

The design of nuclear power plant falls into none of the neat compartments of engineering that we have come to accept. It is not covered wholly by civil, mechanical, electrical or even chemical engineering. It is, in fact, spread across all of them (Editorial 1956).

Even more than Walter Zinn's seminal influence in shaping expertise at ANL (and, by extension, the content of American nuclear engineering), Hinton dominated British understandings of the field; opposing views made little headway. A notable example was J. V. Dunworth, Head of the UKAEA Reactor Division, who argued that reactors were orders of magnitude more complex than conventional power facilities, rejecting 'the frequently expressed view that nuclear engineering is just another branch of ordinary engineering' (Dunworth 1958). Despite a seniority comparable to Martin Shaw's in the USA, Dunworth unsuccessfully promoted nuclear engineering against this institutional momentum.

The UKAEA inherited the staffing structures of its predecessor in the Ministry of Supply that had continued through and after the war. The established civil service categories for technical workers included the Professional class of Scientific Officers (including Assistant, Higher and Executive grades, identified as Chemists, Physicists, Metallurgists or Mathematicians) and Engineers (divided into Chemical, Civil, Electrical and Mechanical); Industrial grades, incorporating a production hierarchy based on the Ordnance Factory system; and Craft workers, traditionally trained by apprenticeship or college courses. In this entrenched system, there was no apparent slot for nuclear workers per se, and no motivation to create a new category. ${ }^{15}$

\footnotetext{
15 In later years, the UKAEA moved from civil service grading to a simpler salary structure, but largely retained the post-war technical categories with isolated additions such as Computing and Electronic, but not Nuclear, Engineer.
} 
Not all agreed even that a new discipline and profession should be centred on engineers. John Cockcroft promoted a division of labour via a science-led, technician-managed profession, observing that 'physicists, chemists and metallurgists are carrying out a vast research program which will enable the engineer to build better power reactors' (Cockcroft 1956). Others in the emerging industry allocated praise more equitably, even if they presented a hierarchy in tune with the UKAEA: an editorial in Nuclear Power marked the opening of Calder Hall as 'the triumphant answer of a dedicated team of scientists, engineers and craftsmen'.

The dissenting views concerning disciplinary novelty were replayed in the professional sphere. As Andrew Abbott has argued, disciplinary and occupational space must be negotiated in the ecology of professions (Abbott 1988). Cockcroft, diffident about pigeon-holing his new experts, was concerned that the formation of an American Nuclear Society in 1954 meant that 'the UK would be placed in an unfavourable position unless it had some corresponding body not under the direct control of our own Atomic Energy Authority'. He argued that existing professional institutions were too fragmented to include 'any appreciable fraction of our scientists' who, in fact, 'would not be eligible'. Instead, he proposed a new society. $^{16}$

Nevertheless, most of his contemporaries favoured a joint effort by three or more existing groups. Individual professional societies had been scouting territory, too. The prominent chemist Sir Harold Hartley argued that atomic energy would shift disciplinary balances: 'with the lure of nuclear physics and electronics, classical physicists were a dying race', he claimed, and 'chemical engineers have to do the research' (Hartley 1953). Christopher Hinton supported Hartley's view that both chemical and nuclear engineering be recast as 'process engineering' (Divall and Johnston 2000). Professional societies, too, sought to extend their remit. In 1955, four institutions - the Civil, Mechanical, Electrical and Chemical Engineerscollaborated with the Institute of Physics to form a joint body for the advancement of nuclear technology: the British Nuclear Energy Conference (BNEC). Significantly, they agreed that the new specialism was "not to be regarded as a completely new technology, but rather as an extension and development of existing technologies' (Hinton 1956). In effect, the organisation promoted a pan-engineering grouping that weakened professional aspirations but worked overtly in the mutual interests of industry, government and established technical institutions. Thus, a template for British nuclear workers was framed by the working practices of earlier engineers.

Unsurprisingly, key players in the BNEC were Christopher Hinton, its first Chairman, and board member John Cockcroft. Hinton personified the union of disciplines, being a Fellow of the Royal Society and member of three of the four Institutions. This movement by existing professions to occupy seemingly vacant professional territory also involved quelling potential invasions. The proposed formation of a separate Institution of Nuclear Engineers (INucE) in 1958, seeking to form a learned society along the lines of the existing British institutions, provoked energetic responses. The Civil and Chemical Engineers rehearsed their argument

${ }^{16}$ Cockcroft, John. memo to unlisted recipients. 22 Nov 1954. NA AB 19/84. 
that the nuclear industry did not bring into being a new kind of engineer, but merely a new challenge in the application of existing branches of engineering (Editorial 1958). The Secretary of the INucE could counter only ineffectually that 'we are a new creation in a new and expanding field and we are tied to none' (Editorial 1966). ${ }^{17}$

\section{Canadian Extension of the Wartime Context}

By contrast, a single site at Chalk River, Ontario, engaged in research and development of atomic energy in Canada while eschewing weapons options. There, the institutionalisation of nuclear engineering shared features of both the American and British experiences. Founded in the final year of the war from the AngloCanadian group based at Montreal (Williams 2000), and directed for a time by John Cockcroft, the isolated facility at Chalk River soon became the largest project of Canada's National Research Council (NRC) and was spun-off in 1952 as a separate Crown Corporation, Atomic Energy of Canada Ltd (AECL).

AECL pursued the Harwell and Oak Ridge model of training, beginning its own training courses for its various professional and craft workers in 1958. Two years later, it instituted the Chalk River Reactor School, but teaching to home and international students 'the basic principles of reactors available to those qualified engineers and scientists who desire to gain practical knowledge in their design and operation'. ${ }^{18}$

Canadian nuclear workers had some unique features, however. As in the UK, preexisting industrial organisation provided a model for the new field. From its origin in 1916, the NRC had been directed by engineers and pursued mainly goal-oriented scientific research, employing a then-unusual complement of scientists, engineers and technicians. This intermingling of disciplines shaped the working culture at Chalk River: the hierarchy of roles common at Argonne and Harwell (scientists above engineers) was downplayed, and there was openness to new and more fluid categories of expertise.

Moreover, Canada had publicly rejected nuclear weapons development (although it benefited indirectly from the plutonium economy, selling plutonium extracted from its reactors solely to the USA). The Canadian work, unlike the British spectrum of efforts in exploring and developing atomic energy, was geographically and intellectually focused. Continuing the wartime research begun in Montreal, Chalk River personnel concentrated on developing a single reactor technology (the heavy-water CANDU reactor system). This further distinguished the expertise of its home-grown nuclear specialists.

A decade after the production of the first atomic bomb, then, nuclear engineering and its specialists were part of a shadowy field. Uniquely for a coalescing discipline, they had been defined by their work for a single employer: their respective

\footnotetext{
17 The INucE never attained the professional cachet of the 'big four' engineering institutions, but offered a commercial periodical and conference venues to bring nuclear workers together.

18 AECL. The university graduate and Atomic Energy of Canada Limited, 1959. Library and Archives Canada (henceforth LAC) MG30 B59 Vol 8.
} 
governments. Their developing expertise remained insulated by secrecy and shaped by regional ambitions or prevailing industrial cultures. Their education took place almost exclusively at, or in collaboration with, government laboratories rather than at universities. This segregation hampered dialogue and integration with other scientific and engineering disciplines, limited their professional aspirations and constrained careers. Thanks to State sponsorship, nuclear engineers in each country were truly a breed apart.

\section{Triggered Release: The Declassification of Nuclear Knowledge}

The first two discrete phases of nuclear engineering — wartime military development from c1940 to 1945 , and then post-war engineering exploration 1946 to c1955vaunted the products of nuclear workers but kept the specialists themselves hidden from public view (Del Sesto 1986, Weart 1988; Forgan 2003). A new phase, c19551962, introducing the nascent discipline to the academic sphere alongside the first commercial exploitation, was again triggered by American initiatives. ${ }^{19}$

The opening act was a 1953 speech to the United Nations by President Eisenhower. 'Atoms for Peace' was the outcome of his government's efforts to publicise to Americans the 'age of peril' created by the loss of the monopoly on nuclear weapons and the growing momentum of the Cold War. Over the following months, however, the US administration, noting that the speech had put the Soviet Union on the defensive, decided to follow up with examples of the social improvement which can be expected to follow from the peaceful application of nuclear energy'. Among the recommendations affecting the teaching of nuclear engineering was a draft plan to open up the Oak Ridge isotopes school to 'instructors and students from all of the free world'; to stimulate discussions 'in the labour and management field' regarding the non-military application of atomic energy; and, most relevantly, 'to endow new chairs, revision, modernization and improved distribution of text books and technical magazines'. ${ }^{20}$ Beginning as a media-wise re-education of the American public, 'Atoms for Peace' opened possibilities for American-led dissemination of not-so-secret atomic secrets and, with it, a more open discipline.

From 1954, American efforts began to focus on explicit training routes. Hanford hosted a School of Nuclear Engineering sponsored by General Electric, and ANL instituted a seven month School of Nuclear Science and Engineering, vaunted by the AEC as 'one of the major projects under the Atoms for Peace program to assist peoples of friendly nations to develop the peaceful uses of atomic energy'. ${ }^{21}$ In 1957

\footnotetext{
19 Subsequent periods, involving consolidation of nuclear power programs c1963-1985 and a subsequent retrenchment of the field following anti-nuclear movements and dramatic failures such as Chernobyl, are beyond the scope of this paper.

20 Operations Coordinating Board. A program to exploit the A-bank proposals in the President's UN speech of December 8, 1953. 4 Feb 1954. Eisenhower Presidential Library, accessed via http://www.eisenhower.utexas.edu/dl/Atoms_For_Peace/Binder11.pdf.

21 Argonne National Laboratory. Minutes. Inter-institution committee for considering a cooperative effort for advanced nuclear engineering education. 20 Dec 1955. UI box 100 .
} 
ORSORT itself linked with a half-dozen higher education institutions to offer a twoyear curriculum in nuclear engineering, and in 1960 it admitted its first nonAmerican students. Brookhaven National Lab, too, could report education measures by the late 1950s. Chief among these was an annual 10-week summer laboratory program and 'a number of ad hoc courses of a few weeks' duration, chiefly for nuclear engineers'. ${ }^{22}$

Eisenhower's initiative prompted international responses. During 1955-exactly a decade after the use of atomic bombs had ended the Second World War, and nearly 15 years after the first research to develop them-nuclear specialists and their expertise became more visible. The event that signalled this flow of information was the first 'International Conference on the Peaceful Uses of Atomic Energy' held in Geneva during the summer of 1955. The Geneva conference represented more than a commemoration and political act; it also promoted the first serious attempts to create a new industry. Eisenhower's political gesture had been followed by legislation, notably the Atomic Energy Act of 1954, which ended the government monopoly of atomic energy processes, production, materials and training. In effect, it opened the possibility of a civilian nuclear era in the United States. Together, 'Atoms for Peace', the revised Atomic Energy Act and the Geneva Conference opened an academic route for nuclear engineering.

The year following the conference, the new Calder Hall power station, the first significant and widely publicised civilian application of nuclear power, was completed next to the Windscale 'plutonium factory' piles in England. The secret activity of bomb production was now twinned with an important civilian application. Nomenclature underwent a transition, too: the wide-ranging atomic energy projects were being recast as more focused nuclear power projects. Post-war enthusiasms for all things atomic were redirected and pared down. Radioisotopes proved important in defining the new field of medical physics (Kraft 2006) and became a small, if profitable, by-product of reactors in several countries (particularly in Canada, where AECL focused its early profit-making aspirations in a Commercial Products Division to market them), and somewhat later in the USA (Creager 2004). In the face of public resistance, the irradiation of foods to extend their shelf-life proved difficult to commercialise (Buchanan 2005). Early spurts of publicity were sidelined, particularly the agricultural hopes for new breeds of crop from irradiated plants and schemes for peaceful civil engineering applications of atomic bombs such as the excavating of hills, harbours and river courses (for analyses of the principal American initiative, Project PLOWSHARE, see, for example, Cosgrove 1998 and Frenkel 1998).

The relaxation of security encouraged key actors to direct the training of a new generation. The UK and USA continued to steer distinct courses in defining nuclear engineers, despite the same nominal goals of bomb development, civil applications and national prestige. And in Canada, without military aspirations or urgency to pursue immediate applications, discipline-building drew increasingly on American experiences. Indeed, from the mid 1950s, a number of countries began to conceive

\footnotetext{
$\overline{22}$ Brookhaven National Laboratory. Brookhaven 1960-1982 and its Associated Universities. UI box 35.
} 
the co-development of nuclear power and nuclear engineering expertise; the case of Spain, for example, has been discussed recently (Salom 2005).

\section{Altering Cross-sections: Avoiding Categorisation in the UK}

As discussed above, in the UK the dominance of established professions, coupled with an ingrained industrial working culture and pragmatic administrators, militated against a university discipline. Nevertheless, new specialist journals, liberated by the lowering of secrecy, lobbied for open training. Nuclear energy demanded, said The Engineer, 'the accumulated knowledge and experience of conventional branches of engineering, adapted in varying degree to meet a new application', although 'the initial problems remains - the dissemination of knowledge to start this process' (Editorial 1955). Nuclear Engineering argued that future educational facilities should exist not only at the atomic energy establishments, but also at schools, universities and technical colleges. The young journal consequently promoted post-graduate education via an annual scholarship for students having a prior degree in engineering, physics, chemistry or metallurgy, the disciplines that it argued were the basis of nuclear engineering.

There were also internal pressures to extend training. The Ministry of Education wanted Technical School courses to take over the Harwell Reactor School's introductory 6 weeks so that it could focus on more advanced topics, and judged that three college courses would suffice for England's manpower requirements. ${ }^{23}$ Harwell itself was tugged by opposing forces during this period: by the need to promote itself as 'a kind of university where the staff, having obtained knowledge and information, were free to go to other universities and instruct people'; to support the UK nuclear power program; and even by distinct groups within the UKAEA who sought diversification outside the field of nuclear energy (Spence 1967). A trickle of further education courses consequently began to appear in 1956, mainly in the form of short introductions. ${ }^{24}$ The proliferation of disparate courses, inspired by entrepreneurial initiatives to capture vaguely defined audiences, encouraged the Ministry of Education to limit and approve validated courses.

In parallel with these introductory courses, Harwell mounted the Reactor School for more advanced training. Much of the curriculum of the 3-month, $150 \mathrm{~h}$ School appeared distinctly novel. ${ }^{25}$ Here again, Christopher Hinton exerted a strong influence. Opposing what he saw as the model of 'some of the American Universities and Colleges of Technology... running training courses for 'nuclear

\footnotetext{
23 Board of Education and successors: Technical Branch and Further Education Branch: Registered Files (T Series). NA ED 46/1062.

24 Early examples included Borough Polytechnic in London, Acton Technical College, Birkenhead Technical College, Battersea Polytechnic, Leeds College of Technology and the North West Kent College of Technology.

25 It included background on reactor theory; engineering (temperature distributions in reactors, thermal stresses and kinetic behaviour of reactors); chemical engineering and metallurgy (manufacturing moderators and fuel elements, and extracting bred fissile material from them); and, more advanced topics such as electromagnetic pumps for liquid metal coolants and various types of power generating reactors.
} 
engineers", his earliest proposals envisaged an extension of university-taught chemical engineering curricula to embrace the new nuclear skills:

In the chemical engineering schools the application has been to the engineering of chemical plants. Might it not be better to broaden our ideas... to process engineering? It then seems to me that we have a fourth major engineering field, and in this field it would be reasonable to include a course of lectures on nuclear engineering. ${ }^{26}$

Hinton lobbied the Universities of Manchester and Cambridge for nuclear energy or process engineering courses suitable for current and anticipated Authority staff. Manchester, well sited for the nuclear sites concentration in northwest England, offered a single post-graduate nuclear engineering course in 1954. Even supporters of the plan, who noted that the head of its Engineering Department was 'really quite keen', reported that nuclear engineering courses within the chemical engineering department were impracticable given the already heavily loaded syllabus.

Frustrated by their lack of response, Hinton was pragmatic about a suitable disciplinary home for such teaching, complaining that Prof T. R. C. Fox (19121962), in the Cambridge Chemical Engineering Department and member of the Atomic Energy Council, was cool to the proposal, unlike his counterpart in Mechanical Engineering: 'Although I always thought that chemical engineering was the proper framework for the new nuclear subjects, if Baker is prepared to take action on the mechanical engineering side I think he should be encouraged'. Similarly, Hinton judged that the University of Manchester's weaker staffing in the 'heavily biased... chemistry side' of its College of Technology would make it easier to 'graft a course in nuclear engineering' onto the Mechanical Engineering offerings. $^{27}$ Disciplinary homes were just as malleable elsewhere. Heriot Watt University was considering a course on Power Generation by Nuclear Reactors within its Electrical Engineering Department. And a survey of Imperial College departments in 1957 indicated that several of them taught a smattering of nuclear subjects. ${ }^{28}$ Influenced by such local university contexts, the emerging discipline thus developed along the parallel lines of expertise in chemical separation and transformation of materials (through chemical engineering) and power generation, thermodynamics, control mechanisms and shielding (through mechanical and, occasionally, electrical engineering).

As suggested by this decanting of expertise into disparate departments, Hinton hoped to shape the nature of its university teaching by situating nuclear engineering as a post-graduate or on-the-job adaptation of conventional engineering skillsrehearsing the experience of his first cohort of UKAEA engineers. Approached to recommend an appointment for a new chair of Nuclear Engineering at Queen Mary College, London, Hinton observed disparagingly that it would be 'difficult to find a

\footnotetext{
${ }^{26}$ Hinton, Christopher, letter to Harold Hartley. 4 Aug 1954. NA AB 19/84.

27 Hinton, Christopher, letters to J. M. Kay. 4 Jan 1955 and 22 Dec 1954. NA AB 19/84.

28 The departments of Physics, Mathematics, Chemistry, Metallurgy and Mechanical Engineering offered some 12-50 h each of lecture-based courses to undergraduate students [letters, Nuclear Science Instruction-UGC enquiry 1957 (File No. 571), 1957. Imperial College Archives, London, UK (henceforth IC) GB $0098 \mathrm{KNP} / 3 / 1$ ].
} 
man with experience in this field' and suggested instead that they pick a conventional academic engineer who could be further trained at Harwell for 6 months. ${ }^{29} \mathrm{He}$ argued privately, 'the last thing we want to do is to treat Nuclear Power as a separate technology' and, a few days later, 'I think that it would be better to think of it as an additional field in which students can practise the application of the basic engineering principles which ought to form the backbone of their University course'. ${ }^{30} \mathrm{He}$ dictated the same message a year later to the newly appointed professor, John Menzies Kay (1920-1995), who had taught chemical engineering at Cambridge from 1948 and had then been Chief Technical EngineerHinton's subordinate-from 1952. Not surprisingly, Kay correspondingly proposed an Authority-inspired curriculum:

It has been suggested in some quarters that 'nuclear engineering' is a basic subject which should take its place alongside civil, mechanical, electrical and chemical engineering. This view, however, is not shared by any engineers of standing who are actively engaged in the development of nuclear power... It has been found necessary within the Atomic Energy Authority and in the engineering industry to build up large teams of mechanical, civil, electrical and chemical engineers to handle these projects. These engineers, while working in the field of nuclear power, and acquiring special knowledge that might be described under the term 'nuclear engineering', in fact remain primarily as mechanical, civil, electrical or chemical engineers, respectively...This point of view also leads naturally to the present proposal for a postgraduate course in nuclear power at Imperial College which would be open to men who have already graduated in one of the recognized basic branches of engineering. ${ }^{31}$

Basing curricula on guesses for the potential market as well as experts such as Hinton meant that the complement and level of university courses varied. ${ }^{32}$ Initially entrepreneurial forays into what the College directors hoped would be a burgeoning market, such courses replaced Ministry-mandated and Harwell-inspired offerings (Divall 1991; Yeo 1997).

The rise of academic training created its own tensions within the UKAEA. The original generation of nuclear workers recruited by Christopher Hinton-pioneers in

\footnotetext{
${ }^{29}$ Hinton, Christopher, letter to T. P. Creed. 23 Nov 1955. NA AB 19/84.

${ }^{30}$ Hinton, Christopher, letters to O. A. Saunders. 5 and 9 Jan 1956. NA AB 7/40.

${ }^{31}$ Kay, John M. Imperial College, 4 Jan 1957. NA AB 19/84.

${ }^{32}$ University: nuclear engineering 1954-1957 Train/1. NA AB 19/84. King's College, Newcastle, predicting the rise of marine applications, discussed a nuclear engineering course oriented towards the naval industry [Advisory Panel in Chemical Engineering. Minutes, 20 Feb 1957. King's College Newcastle archives]. The University of Glasgow instituted a more general course in 1956 shared between the Natural Philosophy (i.e. Physics) and Engineering departments (news item 1956c). Birmingham University began a one-year M.Sc. course in reactor physics and technology in its Physics Department in 1956 and, a year later, Nottingham University offered familiarization courses in nuclear engineering for graduate level students, with Queen Mary College, London, offering a nuclear engineering option in its BSc in Electrical Engineering. Cambridge offered a course on reactor theory and in 1958 Imperial College began graduate courses in Nuclear Power (in the Department of Mechanical Engineering) and Nuclear Technology (in the Department of Chemical Engineering).
} 
the developing art but without formal training-increasingly found themselves sidelined or even demoted in the organisation's hierarchy as a newly trained but inexperienced cohort joined their ranks. As one relegated to a study of workplace contamination complained, he was reduced to polishing brass doorknobs (Millar 1956).

\section{American Academic Definition}

The story was different in the USA. Although triggered by the lowering of security concerns and pressed forward by governmental and industrial pressure to support the emerging nuclear industry, a national consensus developed that supported nuclear engineering as a discipline.

The haste to illustrate the civilian application of nuclear energy drove academic nuclear engineering. During the late 1950s American universities began to usurp the role of Oak Ridge's seminal course, ORSORT, in training nuclear workers and, with strong government incentives, strove to expand the academic presence of nuclear engineering. In the face of predictions of an annual national demand for some ' 2,000 engineers and scientists-mostly engineers', power company executives in the southern states lobbied for government support of college and university training programs. Demonstration projects such as the Nautilus submarine and nuclear power plants created a demand for 'design engineers, construction supervisors, operating and maintenance engineers... specifically trained for this field and fully aware of its stringent requirements' (Folger and Meeks 1957, p. 116).

Nevertheless, the national laboratories, along with their associated university consortia, played a diffident role in defining educational standards for the new subject and transferring teaching responsibility to academic institutions. In 1955, for example, ANL sponsored an 'inter-institution committee for considering a cooperative effort for advanced nuclear engineering education' with eight of its participating universities. Norman Hilberry, its Deputy Director, argued that 'engineers... need a greater appreciation of the nuclear problems... than would come from their cursory associations during their undergraduate years', but the deficit could be made up by an increase in Argonne's teaching facilities. ${ }^{33}$ Indeed, it seemed that universities were not up to the mark. Andrew Longacre, the University of Illinois representative, more pointedly suggested the frustrations felt by university departments tasked with teaching nuclear engineering. His argument, widely shared among his colleagues, stressed the promiscuous sources of the new subject, which

rested upon essentially a relatively small number of scientists. There had been no nuclear engineering prior to the war, and the requirements... had no counterpart in any other field of engineering. The people that pioneered nuclear technology were of various backgrounds and developed their proficiency by on-the-job training and experience. ${ }^{34}$

\footnotetext{
33 Argonne National Laboratory. Minutes, Inter-institution committee for considering a cooperative effort for advanced nuclear engineering education. 20 Dec 1955. UI box 100.

34 Longacre, Andrew. 'Proposal for a cooperative facility for education in nuclear engineering', Nov 1955. UI Box 100.
} 
Longacre warned that introducing nuclear engineering curricula comparable to those in other branches of engineering would be difficult, 'owing to the lack of adequately trained staff ... Government laboratories and industrial contractors absorbed the few persons receiving on-the-job training or formal education in those schools offering anything resembling appropriate courses'. The first generation of academic staff had relatively brief industrial experience and engineering degrees in other subjects supplemented by short courses that could be traced back to ORSORT. Few universities, he suggested, would be able to attract competent teaching staff, and "would either have to wait before instituting nuclear engineering curricula or cope with an inferior staff'. Even worse, he observed that the intellectual foundations of the field were unsettled. Unlike established academic fields, nuclear engineering did not have even 'tacit agreement fostered by text books and professional societies, etc., as to what constitutes adequate preparation' ${ }^{35}$

While recognising these problems, the committee opted to press ahead with higher education programs, deciding that each institution should, with government support, provide the courses and facilities necessary for a core program in nuclear engineering on their own campuses. In return, ANL would provide more elaborate facilities and serve as a 'finishing' school for graduate students and for short courses, conferences and teacher training.

The fraught transition from restricted education at the national labs to an open university environment was nevertheless enduring. The chronic shortage of trained staff to meet the rapid expansion, as signalled by Longacre in the mid-1950s, continued. Exacerbating the lack of teaching materials was the scarcity of qualified teachers, most of whom had received some first-hand experience with nuclear reactors and equipment in an AEC laboratory. ${ }^{36}$ The University of Cincinnati advertised desperately in 1959 for 'a staff scientist who is preferably an Experimental Physicist, Electrical Engineer, Nuclear Engineer or someone with a $\mathrm{Ph} . \mathrm{D}$ in any of the other engineering areas. Experience in the area of reactor operation is desirable, but not necessary... ${ }^{37}$ Some early nuclear engineering programs were forced to define criteria of expertise in relation to the handful of basic texts, one advertisement requiring 'a good working knowledge of reactor analysis at the Glasstone and Edlund level' ${ }^{38}$

As this quotation suggests, texts were an important early channel for defining and consolidating the content of nuclear engineering in the USA. Pile Theory, the first and influential text on the theory of reactors, was a summary of ORSORT lectures

\footnotetext{
35 Ibid.

36 The University of Arizona, for example, began a programme in 1959 under Lynn Weaver (b 1930). Weaver had not worked on the Manhattan project or national laboratories but, with two degrees in electrical engineering under his belt, gained experience from 1953 on a Convair Corporation programme to design a nuclear-powered bomber, where he began to study reactor control problems. Weaver took one course from a graduate of ORSORT, and absorbed more from the handful of texts then becoming available. Most of his half-dozen teaching staff had worked at an industrial firm, General Atomics, contracted to produce a reactor design for space flight applications [Weaver, Lynn. Interview with Sean F. Johnston. 3 Mar 2007].

37 Roberson, John H., letter to Warren F. Stubbins. 28 Sep 1959. UI box 83.

38 Iowa State University. Dept of Nuclear Engineering advertisement 27 Sep 1960. UI box 83.
} 
by four Met Lab physicists (Soodak and Campbell 1950). The 71 page simplified exposition was later superseded by a considerably expanded treatment (Glasstone and Edlund 1952) but as the foreword to Pile Theory emphasised, 'the greatest part of the work is still classified, and probably will remain so for some time' [p. vii].

The dearth of a suitable catechism of instruction was apparent to educators. A professor of Engineering Mechanics noted that

the choice of textbooks from which to teach ... is very limited, and the majority of the texts published to date have been written by nuclear scientists rather than professional educators. As a result, books in this field are characterized (from the teacher's viewpoint) by poor arrangement of topics, lack of continuity and integration of approach to the subject, completely inadequate problems for student solution, both in quantity and in nature, and by inconsistency of numerical data. It is also noticeable from the textbooks that, unlike the situation in many other engineering fields, very few standard analytical methods and design techniques have been developed. ${ }^{39}$

Academics were faced with the problem of defining adequate curricula for the still malleable intellectual foundations of the field, but were equally challenged in specifying the desirable characteristics of their graduates, shaped by rapidly developing industrial opportunities. Notre Dame University, for instance, opted for a graduate program 'with the emphasis on fundamental concepts rather than on technology. The program of instruction was originally conceived as one in reactor physics and in instrumentation, built on a sound background in atomic and nuclear physics and on some chemical physics'. ${ }^{40}$ Other institutions stressed engineering design, but all struggled to obtain adequate laboratories and competent teachers.

The difficulties in hastily defining an adequate intellectual basis for a curriculum are further illustrated by the case of Wayne State University. Government pressures were an important consideration in motivating a program: its Associate Professor of Engineering Mechanics felt 'an obligation to provide training and education in the rapidly expanding field of nuclear science and engineering' imposed by 'the hundreds of millions of dollars allocated by the AEC to the objective of promoting education in this field'. But his enthusiasm was tempered; he cautioned that the rapid evolution of the field, pressed by strong government direction, made teaching the subject difficult:

Nuclear Engineering is still extremely young as branches (or sub-branches) of engineering go; it is still changing with a rapidity almost unprecedented in the evolutionary history of technology (even so-called 'fundamental constants' may vary from day to day); opinions of both professional educators and practitioners in the field still diverge widely over what constitutes a proper nuclear engineering education. ${ }^{41}$

\footnotetext{
39 Perry, C. C. memo. Nuclear engineering at Wayne State University. 6 Apr 1959. UI box 22.

${ }^{40}$ Newman, M. K., letter to J. H. Roberson. 17 Feb 1960. UI box 85.

41 See note 39.
} 
His concerns were echoed by many academics and university administrators at the end of the decade. Even the Director of the Associated Midwest Universities, closely linked to ANL, responded to one potential student of the subject, 'I am somewhat reluctant to offer any guidance with respect to the comparability of the nuclear engineering programs because it is a difficult subject and I am not too well versed'. ${ }^{42}$

In 1958 a Nuclear Engineering Education Committee (NEEC) was formally established by the Midwest universities collaborating with ANL (Greenbaum 1971), seeking to formulate policies on university cooperation with ANL and on educational programs originated by the AEC. Its vision of nuclear engineering was nevertheless contested then and later-a legacy of the National Laboratory system and, in particular, the role of Walter Zinn in defining the remit of ANL.

There were, then, crucial elements impeding the process of disciplinisation at American universities: a shortage of qualified practitioners and educators; an absence of suitable teaching materials and course curricula; and, a lack of an authoritative body of experts able to define, approve and regulate academic standards in the field.

To address such concerns, the Atomic Energy Commission consulted with an established organisation, the American Society for Engineering Education (ASEE) and its new Nuclear Committee, to establish programs that would procure appropriate equipment for university departments, publish texts and develop faculty. From 1960, this was extended with the involvement of the young American Nuclear Society (ANS). Noting that 'current programs differ significantly from one another because of varying educational philosophies among institutions as well as differences in calibre, education, and experience of faculties', the ANS and ASEE study set out to identify 'the attributes of formal education in nuclear engineering', and with it the means of accrediting nuclear engineers. ${ }^{43}$ Their report was seminal in defining the American discipline and profession.

Having no British or Canadian counterpart, the ANS/ASEE committee argued for the existence of a new technical discipline rather than a cobbled-together assortment of subjects. It specified nuclear engineering as 'that branch of engineering directly concerned with the release, control and utilization of all types of energy from nuclear sources':

Nuclear engineering includes the design and development of systems, such as fission or fusion reactors, for the controlled release of nuclear energy and the applications of radiation... The central area of interest in nuclear engineering involves the solution of those problems in which the unique nature of nuclear energy presents the major challenge. Typical nuclear engineering problems arise, for example, from the high effective temperatures which occur at the instant of energy release, the intense radiation of photons or particles which accompany the release process, the factors involved in maintaining the energy release on a continuous, controlled basis, the necessity for protection of

\footnotetext{
42 Roberson, John H., letter to E. L. Multhaup. 11 Apr 1960. UI box 83.

43 American Nuclear Society 1960. ASEE Report on objective criteria in nuclear engineering education. Queens University Archives, Kingston, Canada, Sargent fonds, Series III Box 4.
} 
personnel from radiation, including the safe handling of reactor materials, irradiated materials and radioisotopes, and the use of radioactive materials. ${ }^{44}$

Nuclear engineers, they argued, required expertise in reactor analysis and design; analysis of radiation effects; shielding design; utilisation of radiation, processing and control of radioactive materials, and nuclear energy systems design. The committee argued that its list of essential and unique content made a strong case for demarcating a discipline.

As a degree of uniformity spread through American university curricula, Higher Education adapted to teach employed workers and, even more importantly, university educators themselves. Educators and commercial nuclear engineers of the first generation were typically taught via one- to two-month summer courses, funded jointly by the AEC and the universities; thereafter, regular undergraduate and graduate courses became the norm. As a discipline, American nuclear engineering thus saw a two-decade transition from direct government sponsorship to increasing industrial and academic definition. In 1965 ORSORT-the post-war paradigm for the new American discipline-finally closed as more independent university programs became established. Perhaps the best recognition of the nascent discipline and profession was the attention drawn to it by at least one sociological study (Vollmer and Mills 1962). ${ }^{45}$ By the mid 1960s, then, American nuclear engineering—unlike its British counterpart—had been established in the academic sphere. ${ }^{46}$

\section{Conclusion: A State-managed Discipline}

The implantation of nuclear engineering in the academic realm represents an unusual case of disciplinary formation. Not only was it distinctly different in three of the first countries in which it occurred, but also was directed explicitly by their respective governments. Indeed, this account focuses relatively little on engineers themselves in advancing discipline creation, and devotes attention instead to State institutions, senior officials, technical administrators and educators. This unusual 'outside-in' construction of an academic field is unique to nuclear engineering. At least three key factors can be identified to explain these national trajectories.

First, the constraints of secrecy imposed by wartime security and the post-war McMahon Act created regionally distinct profiles of nuclear workers and early educators. Similar security policies in the UK and Canada, both of which sought to resume more open relations with the American nuclear program, inhibited an academic identity for the subject through the 1950s.

\footnotetext{
44 Ibid.

45 Extending the studies of industrial sociologist Nelson N. Foote on the American car industry, Vollmer and Mills argued that nuclear technology showed evidence of 'rudimentary professionalization of labour', notably theoretical formulations supporting specialised techniques, collegial association of its experts, growing recognition by a wider community, and an awareness of public health and safety as a criterion of professional responsibility.

46 The Canadian implementation was along similar disciplinary lines to its American counterpart, but chronically limited by small student numbers and relatively few occupational sites.
} 
Second, existing technical cultures, particularly in the UK and Canada, imposed their labour categories on nuclear workers. Christopher Hinton, the powerful shaper of the British nuclear production organisation, mapped the expertise of nuclear workers onto wartime civil service chemical workers and thereby damped occupational, disciplinary and professional ambitions. And in Canada, Chalk River inherited the norms of disciplinary cooperation developed at the pre-war National Research Council. Segregated national laboratories further encouraged divergent working cultures. AEC administrators such as Walter Zinn at ANL assembled disciplinary groupings that mirrored their own background.

Third, the involvement of the State (via the AEC in the USA, UKAEA in Britain and AECL in Canada) determined both the goals and pace of academic representation. The creation of nuclear industries during the late 1950s in these countries, driven by active government promotion, was accompanied by sponsorship of hastily mounted, and often ambiguously conceived, university programs. ${ }^{47}$ In contrast to other engineering disciplines, then, which in general entered academe more slowly and with closer industrial alliances, the emergence of nuclear engineering in its variant national forms was a story of a State-managed discipline.

Acknowledgements The funding of this work by Economic and Social Research Council grant RES000-22-2171 is gratefully acknowledged. The helpful comments of colleagues and two anonymous referees of Minerva are also much appreciated.

\section{References}

Abbott, Andrew D. 1988. The system of professions. Chicago: University of Chicago Press.

Bernstein, Jeremy. 2004. Oppenheimer: Portrait of an enigma. London: Duckworth.

Bothwell, Robert. 1988. Nucleus: The history of atomic energy of Canada Limited. Toronto: University of Toronto Press.

Brown, Andrew. 1997. The Neutron and the Bomb. Oxford: Oxford University Press.

Buchanan, N. 2005. The atomic meal: the cold war and irradiated foods, 1945-1963. History and Technology 21: 221-249.

Carlisle, Rodney P., and Joan M. Zenzen. 1996. Supplying the nuclear Arsenal. Baltimore: Johns Hopkins Press.

Cockcroft, John D. 1954. Foreword. The Journal of Nuclear Energy 1: 1.

Cockcroft, John D. 1956. Scientific problems in the development of nuclear power. Nuclear Power 1: 200.

Compton, Arthur H. 1956. Atomic quest. Oxford, Oxford: University Press.

Cosgrove, Denis. 1998. Introduction: Project plowshare. Cultural Geographies 5: 263-266.

Creager, Angela N.H. 2004. The industrialisation of radioisotopes by the US Atomic Energy Commission. In The science-industry Nexus, ed. Karl Grandin, and Nina Wormbs. New York: Watson Publishing.

de Leon, Peter. 1979. Development and diffusion of the nuclear reactor. Cambridge MA: Ballinger.

Del Sesto, Stephen L. 1986. Wasn't the future of nuclear energy wonderful? In Imagining tomorrow, ed. Joseph J. Corn. Cambridge MA: MIT Press.

Divall, Colin. 1991. Fundamental science versus design: Employers and engineering studies in British Universities, 1935-1976. Minerva 29: 167-194.

\footnotetext{
47 The experiences of the period 1940-c1990, dubbed by nuclear engineer Alvin Weinberg 'the first nuclear era', may offer lessons for rapidly mounted government initiatives to rebuild nuclear engineering expertise inspired by efforts to limit climate change.
} 
Divall, Colin, and Sean F. Johnston. 2000. Scaling up: The Institution of Chemical Engineers and the Rise of a New Profession. Dordrecht: Kluwer Academic.

Downey, Gary L., and Juan C. Lucena. 2004. Knowledge and professional identity in engineering: Codeswitching and the metrics of progress. History and Technology 20: 393-420.

Dunworth, John V. 1958. It's not just ordinary engineering. Nuclear Power 3: 36.

Editorial. 1955. The Engineer 200: 569.

Editorial. 1956. Another industrial revolution? Nuclear Engineering 1: 1.

Editorial. 1958. British Nuclear Energy Conference. Chemical Engineer 10: A47.

Editorial. 1966. From the secretary. Nuclear Energy: 31.

Folger, J.K., and M.L. Meeks. 1957. Educated manpower: Key to nuclear development. In Nuclear energy in the south, ed. Redding Sugg Jr. Baton Rouge: Louisiana University Press.

Forgan, Sophie. 2003. Atoms in Wonderland. History and Technology 19: 177-196.

Frenkel, Stephen. 1998. A hot idea? Planning a nuclear canal in Panama. Cultural Geographies 5: 303309.

Glasstone, Samuel, and Milton C. Edlund. 1952. The elements of nuclear reactor theory. Princeton: Van Nostrand.

Gowing, Margaret. 1964. Britain and atomic energy, 1939-1945. New York: St Martin's Press.

Greenbaum, Leonard. 1971. A special interest: The atomic energy commission, Argonne national laboratory, and the Midwestern Universities. Ann Arbor: University of Michigan Press.

Hartcup, Guy, and T. Edward Allibone. 1984. Cockcroft and the atom. Bristol: Adam Hilger.

Hartley, Harold. 1953. Chemistry and Industry 15 Apr 1953, pp. 404-405.

Herken, Gregg. 1980. 'A most deadly illusion': The atomic secret and American Nuclear Weapons Policy, 1945-1950. Pacific Historical Review 49: 51-76.

Herran, Néstor. 2006. Spreading nucleonics: The isotope school at the Atomic Energy Research Establishment, 1951-67. British Journal for the History of Science 39: 569-586.

Hewlett, Richard G., and Francis Duncan. 1969. A history of the United States Atomic Energy Commission, vol. 3. University Park: Pennsylvania State University Press.

Hewlett, Richard G., and Francis Duncan. 1974. Nuclear Navy, 1946-1962. Chicago: University of Chicago Press.

Hinton, Christopher. 1956. Inaugural address. Journal of the British Nuclear Energy Conference 1: 1-2.

Kraft, Alison. 2006. Between medicine and industry: Medical physics and the rise of the radioisotope, 1945-1965. Contemporary British History 20: 1-35.

Millar, R.N. 1956. Future power programme in Britain. Nuclear Engineering 1: 304.

Oak Ridge National Laboratory. 2002. ORSORT: Oak Ridge School of Reactor Technology. Oak Ridge Nuclear Laboratory Review 25: 3-4.

Jay, Kenneth. 1956. Calder hall: The story of Britain's first atomic power station. London: Methuen.

Pocock, Rowland F. 1977. Nuclear power: Its development in the United Kingdom. London: Unwin Brothers.

Poor, R.S. 1963. The Atomic Energy Commission and nuclear education. Interrelated Role of Federal Agencies and Universities in Nuclear Education Conference. Gatlinburg, TN: Atomic Energy Commission.

Salom, Francesc. 2005. Nuclear power for Catalonia: the role of the Official Chamber of Industry of Barcelona, 1953-1962. Minerva 43: 163-181.

Soodak, Harry, and Edward C. Campbell. 1950. Elementary Pile theory. New York: Wiley.

Spence, Robert. 1967. Twenty-one years at Harwell. Nature 314: 343-348.

Vollmer, Howard M., and Donald L. Mills. 1962. Nuclear technology and the professionalization of labor. American Journal of Sociology 67: 690-696.

Weart, Spencer. 1988. Nuclear fear. Cambridge MA: Harvard University Press.

Weinberg, Alvin M. 1994. The first nuclear era: The life and times of a technological fixer. New York: AIP Press.

Williams, Michael M.R. 2000. The Development of Nuclear Reactor Theory in the Montreal Laboratory of the National Research Council of Canada (Division of Atomic Energy) 1943-1946. Progress in Nuclear Energy 36: 239-322.

Yeo, Frances E.M. 1997. Nuclear engineering education in Britain. University of Manchester, UK: MA dissertation. 